\title{
Targeting the FLT3 Mutation in Acute Myeloid Leukaemia
}

\author{
Sabine Kayser ${ }^{1}$ and Richard F Schlenk ${ }^{2,3}$ \\ 1. University of Heidelberg, Heidelberg, Germany; 2. Department of Internal Medicine V, University Hospital of Heidelberg, Heidelberg, \\ Germany; 3. Department of Internal Medicine V, Clinical Cooperation Unit Molecular Hematology/Oncology, German Cancer Research Center
} (DKFZ), University of Heidelberg, Heidelberg, Germany

\begin{abstract}
A cute myeloid leukaemia (AML) exhibiting an internal tandem duplication of the FLT3 gene (FLT3-ITD) is an aggressive haematologic malignancy with a poor prognosis due to a high relapse rate and very limited options after relapse with conventional salvage regimens, whereas the prognostic impact of point mutations in the tyrosine kinase domain of the FLT3 gene (FLT3-TKD) are lesS clear. A number of tyrosine kinase inhibitors (TKIS) have been developed that inhibit the constitutively activated kinase activity caused by the FLT3 mutation, thus interrupting signalling pathways. Early clinical trials of these agents as monotherapy failed to elicit enduring complete responses, leading to clinical testing of FLT3 TKI in combination with conventional chemotherapy. Midostaurin has demonstrated improved survival in combination with standard intensive chemotherapy as compared to standard chemotherapy alone in younger adult patients with newly diagnosed FLT3-mutated AML and is the first and currently the only approved FLT3 TKI. Newer, more selective compounds, such as gilteritinib and crenolanib, have also demonstrated significant potency and specificity. Several combination trials are ongoing or planned in both relapsed and newly diagnosed AML patients with activating FLT3 mutations.
\end{abstract}

\section{Keywords}

Acute myeloid leukaemia, FLT3 mutations, tyrosine kinase inhibitors, intensive chemotherapy, allogeneic stem cell transplantation

Disclosure: Sabine Kayser is a member of the speakers bureau of Novartis, and Teva, and also gratefully acknowledges the support of the Olympia-Morata programme from the Medical Faculty of the University Heidelberg. Richard Schlenk has received research funding from Novartis, Pfizer, Amgen, Teva, AstraZeneca, and from Novartis, Pfizer, Amgen, Teva, AstraZeneca, and
PharmaMar, is a member of the speakers' bureau of PharmaMar, is a member of the speakers' bureau of the advisory boards for Daiichi Sankyo, Novartis, Pfizer. Acknowledgements: Medical writing support was provided by Katrina Mountfort and supported by Novartis. Authorship: All named authors meet the International Committee of Medical Journal Editors (ICMJE) criteria for authorship of this manuscript, take responsibility for the integrity of the work as a whole, and have given final approval to the version to be published.

Compliance with Ethics: This study involves a review of the literature and did not involve any studies with human or animal subjects performed by any of the authors.

open Access: This article is published under the Creative commons Attribution Noncommercial License, which permits any non-commercial use, distribution, adaptation and reproduction provided the original author(s) and source are given appropriate credit.

Received: May 5, 2017

Accepted: May 31, 2017

Citation: European Oncology \& Haematology, 2017;13(2):139-46

Corresponding Author: Richard F Schlenk, NCT Trial Center, National Center for Tumor Diseases, Im Neuenheimer Feld 130.3, 69120 Heidelberg, Germany. E: richard.schlenk@nct-heidelberg.de

Support: The publication of this article was supported by Novartis.
Acute myeloid leukaemia (AML) is a heterogeneous clonal disorder of haematopoietic progenitor cells resulting in uncontrolled growth and accumulation of malignant white blood cells. It is the most common myeloid leukaemia in adults, with a prevalence of 3-8 cases per 100,000 adults rising to 9-17 cases per 100,000 adults aged 65 years and older. The median age at presentation is about 70 years. ${ }^{1} \mathrm{AML}$ affects both male as well as female patients with a slight predominance of the male gender (m/f: 3:2). According to the American Cancer Society, AML accounted for approximately $33 \%$ of all new leukaemia cases in the United States in 2016. Almost 20,000 patients had been newly diagnosed with AML in 2016 in the United States and over 10,000 died of the disease (www.cancer.org). The median overall survival (OS) after 5 years in younger (18-60 years) adult AML patients is roughly $40 \%$ with the disease being even more detrimental in older individuals with only around $10 \%$ surviving patients above the age of 60 years. ${ }^{2}$ Hence, there is a high medical need to improve the outcome of AML patients.

The prognosis for patients with AML is determined to a large degree by the biology of the disease. In recent years, the identification and characterisation of genetic aberrations has vastly improved our understanding of the pathogenesis of AML. These genetic alterations allow for the stratification of patient populations into different risk groups, thus guiding treatment. Based on the currently updated version of the European LeukemiaNet (ELN) risk stratification by genetics, the risk groups consist of the favourable, intermediate and adverse risk categories (Table 1)..$^{3-7}$

AML with normal karyotype (accounting for roughly $50 \%$ of the patients) can be categorised according to molecular abnormalities. Of these, the most frequently affected gene mutations are NPM1 and FLT3. ${ }^{8}$

Despite the fact that $\mathrm{AML}$ is a clinically and genetically heterogeneous disease, until recently most patients have been treated by similar chemotherapeutic regimens. ${ }^{9}$ To date, the only approved targeted therapies for patients with AML are all-trans retinoic acid ${ }^{10}$ and arsenic trioxide ${ }^{11}$ for acute promyelocytic leukaemia (APL), which accounts for $10-15 \%$ of AML cases. ${ }^{12}$

There is a clear need for more targeted therapies and a more individualised approach in the treatment of AML. However, in the last decade the treatment options for AML have expanded as a result of the discovery of cytogenetic abnormalities as well as molecular mutations, but only two new nontargeted drugs have been approved in the EU in this period. This article aims to discuss mutations of the FLT3 gene, as well as the therapeutic interventions targeting these mutations. 
Table 1: 2017 European LeukemiaNet risk stratification by genetics ${ }^{3}$

\begin{tabular}{|c|c|}
\hline Risk Category & Genetic Abnormality \\
\hline Favourable & $\begin{array}{l}\mathrm{t}(8 ; 21)(\mathrm{q} 22 ; \mathrm{q} 22.1) ; \text { RUNX1-RUNX1T1 } \\
\text { inv(16)(p13.1q22) or t(16;16)(p13.1;q22); CBFB-MYH11 } \\
\text { Mutated NPM1 without FLT3-ITD or with FLT3-ITD low* } \\
\text { Biallelic mutated CEBPA }\end{array}$ \\
\hline Intermediate & $\begin{array}{l}\text { Mutated NPM1 and FLT3-ITD high* } \\
\text { Wild type NPM1 without FLT3-ITD or with FLT3-ITD low* (w/O } \\
\text { adverse risk genetic lesions) } \\
\text { t(9;11)(p21.3;q23.3); MLLT3-KMT2A** } \\
\text { Cytogenetic abnormalities not classified as favourable or } \\
\text { adverse }\end{array}$ \\
\hline Adverse & $\begin{array}{l}\mathrm{t}(6 ; 9)(\mathrm{p} 23 ; \mathrm{q} 34.1) ; \text { DEK-NUP214 } \\
\mathrm{t}(\mathrm{v} ; 11 \mathrm{q} 23.3) ; \text { KMT2A rearranged } \\
\mathrm{t}(9 ; 22)(\mathrm{q} 34.1 ; \mathrm{q} 11.2) ; B C R-A B L 1 \\
\text { inv(3)(q21.3q26.2) or t(3;3)(q21.3;q26.2); GATA2, MECOM(EVI1) } \\
-5 \text { or del(5q);-7; -17/abn(17p) } \\
\text { Complex karyotype,\# monosomal karyotype++ } \\
\text { Wild type NPM1 and FLT3-ITD high* } \\
\text { Mutated RUNX1*** } \\
\text { Mutated } A S X L 1^{* * *} \\
\text { Mutated TP53+ }\end{array}$ \\
\hline
\end{tabular}

*Low, low allelic ratio (<0.5); high, high allelic ratio ( $>0.5)$; as determined by Genescan analysis. **The presence of $t(9 ; 11)(p 21.3 ; q 23.3)$ takes precedence over rare, concurrent adverse-risk gene mutations. \#Three or more unrelated chromosome abnormalities in the absence of one of the World Health Organization-designated recurring translocations or inversions, i.e., $t(8 ; 21)$, inv (16) or $t(16 ; 16), t(9 ; 11), t(v ; 11)$ $(v ; q 23.3), t(6 ; 9)$, inv(3) or $t(3 ; 3)$; AML with BCR-ABL1. ++Defined by the presence of one single monosomy (excluding loss of $X$ or $Y$ ) in association with at least one additional monosomy or structural chromosome abnormality (excluding core-binding factor monosomy or structural chromosome abnormality (excluding core-binding factor
AML). ${ }^{* \star \star *}$ These markers should not be used as an adverse prognostic marker if they co-occur with favourable-risk AML subtypes. +TP53 mutations are significantly associated with AML with complex and monosomal karyotype. ${ }^{5-7}$

\section{Activating mutations in acute myeloid leukaemia}

A number of cytogenetic abnormalities, mutations or epigenetic alterations, which are involved in the pathogenesis of leukaemia, have been identified (Figure 1). ${ }^{13}$

Activating mutations of $F L T 3$, resulting in the constitutive activation of this receptor tyrosine kinase, are among the most frequent molecular abnormalities in AML and are present in about $30 \%$ of newly diagnosed patients. ${ }^{14,15}$ FLT3 is a member of the class III receptor tyrosine kinase family and has an established role in normal growth and differentiation of haematopoietic precursor cells. ${ }^{16}$ Following ligand binding, the FLT3 receptor dimerizes at the plasma membrane, leading to a conformational change in its activation loop that allows adenosine triphosphate (ATP) access to the FLT3 active site. This is followed by autophosphorylation and activation of numerous downstream signalling pathways. 17-19 Mutations of the FLT3 gene lead to ligand-independent activation and dysregulation of downstream pathways such as PI3K/AKT, MAPK/ERK and STAT5. ${ }^{20-22}$ These pathways inhibit apoptosis and differentiation, and promote proliferation. The frequency of mutated FLT3 in AML, its location on the cell surface and its association with an adverse prognosis make it an attractive target. ${ }^{23}$

\section{Internal tandem duplications}

The most common FLT3 mutations are internal tandem duplications (ITDS), which occur in roughly 20-30\% of all AML patients, particularly, not only in cytogenetically normal AML, ${ }^{13,24}$ but also in APL with $\mathrm{t}(15 ; 17)$ (q22;q12) and AML with $\mathrm{t}(6 ; 9)(\mathrm{p} 23 ; \mathrm{q} 34)$. Its incidence is associated with age: it can only be rarely found in children, whereas its incidence is highest in young adults up to the age of 60 years and declines in
Figure 1: Mutations in acute myeloid leukaemia ${ }^{13}$

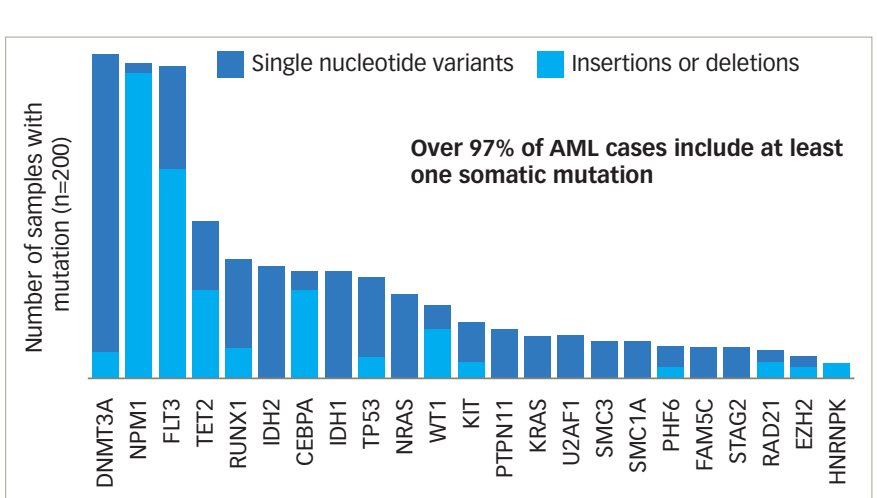

$A M L=$ acute myeloid leukaemia. Reproduced with permission from The Cancer Genome Atlas Research Network. ${ }^{13}$

the elderly. ${ }^{24}$ Clinically, FLT3-ITD mutations are associated with a high white blood cell count, a high percentage of myeloid blast cells in the peripheral blood and bone marrow, and a more frequent diagnosis of de novo rather than secondary AML. ${ }^{25,20}$

In cytogenetically normal AML the presence of an ITD is associated with an increased relapse rate and reduced OS as compared to wild type FLT even after allogeneic haematopoietic stem cell transplantation (allo HSCT). ${ }^{28}$ FLT3-ITD is also a negative prognostic factor for survival in patients with either refractory or relapsed AML as they have a poor response to salvage therapy. ${ }^{29-32}$

Regarding specific ITD characteristics, the size of these duplications varies widely, typically ranging from 3 to over 100 base pairs (bps) with a median of $48 \mathrm{bps} .{ }^{33}$ In addition, size and ITD insertion site in the FLT3 gene seem to be correlated in that the more 3 s the insertion site, the longer the ITD is. ${ }^{33}$ The impact of the size on outcome is still unclear with some publications stating that there is no impact on outcome, ${ }^{34,35}$ whereas one publication found that short ITDs may impart an unfavourable outcome. ${ }^{36}$ Nevertheless, most publications stated that longer ITDs correlate with lower complete response (CR) rates and shorter OS and event-free survival (EFS). ${ }^{37-39}$

Recently, the ITD insertion site within the FLT3 gene has been shown to be an important prognostic factor. ${ }^{33}$ About three-quarters of FLT3-ITDS occur in the juxtamembrane domain (JMD) whereas one-quarter in the tyrosine kinase domain 1 (TKD1) of the FLT3 gene, particularly in the $\beta 1$-sheet. ${ }^{33}$ In cell culture analyses, a prototypic FLT3-ITD with insertion site in the $\beta 2$-sheet of the TKD1 (FLT3-ITD627E) mediated phosphorylation of FLT3 and STAT5, suggesting that non-JMD FLT3-ITD mutations confer constitutive activation of the receptor. ${ }^{40}$ In addition, FLT3-ITD627E induced transformation of haematopoietic 32D cells and led to a lethal myeloproliferative disease in a syngeneic mouse model. Insertions in the $\beta 1$-sheet of TKD1 may introduce a greater instability into the protein structure and may therefore be associated with a pronounced adverse

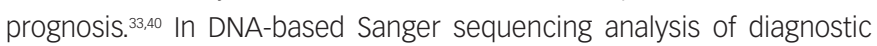
samples from 241 FLT3-ITD mutated patients, an ITD insertion site in the $\beta 1$-sheet of the TKD1 was associated with an inferior prognosis as compared to other insertions sites in terms of achievement of complete remission (CR; odds ratio [OR], 0.22; $\mathrm{p}=0.01$ ), relapse-free survival (RFS; hazard ratio $[H R], 1.86 ; p<0.001)$ and $O S(H R, 1.59 ; p=0.008) .^{33}$

Besides the insertion site, further prognostic and predictive impact has been shown for the allelic ratio, which is quantified by Genescan analysis using DNA fragment analysis. ${ }^{41,42}$ This method is a semi-quantitative 
assessment of the FLT3-ITD allelic ratio, expressing the allelic ratio as a percentage of the area under the curve for FLT3-ITD divided by the area under the curve for wild-type FLT3. According to different publications the distribution of the allelic ratio varies widely. $33,3,3,3,42,43$ Therefore, the question arises where the optimal cut-off value should be to distinguish patients with high versus low allelic ratio. Currently, there is still a lack of consensus on clinically relevant cut-offs between high/low allelic ratios, which might be due to different methodologies of testing that had been applied. Nevertheless, there is a clear association of an inferior OS and EFS in patients with higher allelic ratios.33,38,42,44 In addition, as AML evolves from diagnosis to relapse, the allelic ratio seems to increase. ${ }^{45,46}$ However, in a small proportion of relapses FLT3-ITD was no longer detectable.47

\section{Point mutations of the tyrosine kinase domain}

In addition, approximately 5-10\% of AML patients harbour point mutations within exon 20 of the FLT3 gene (FLT3-TKD). ${ }^{22}$ TKD mutations most frequently occur at codon 835 where a tyrosine residue replaces aspartic acid, stabilising the activation loop in the ATP-bound configuration and promoting activation. ${ }^{48}$ Other point mutations include, for instance, N676D, 1836S and Y842C in the TKD1 and TKD2 domains, respectively. ${ }^{49}$ Unlike ITDS, the incidence of point mutations is not associated with age ${ }^{50}$ and their prognostic significance is discussed controversially. ${ }^{14,4,4,4,51-54}$ Nevertheless, TKD mutations can occur after treatment with tyrosine kinase inhibitor (TKI) as a mechanism of resistance, thus implicating an adverse prognosis. ${ }^{55-57}$

\section{Concurrent mutations}

The prognostic impact of FLT3-ITD is also affected by concurrent mutations, such as nucleophosmin 1 (NPM1) and DNMT3A. In normal karyotype AML (CN-AML) with NPM1 mutation, FLT3-ITDS are present in about $45 \%$ of patients. ${ }^{58.59}$ Mutations in exon 12 of the NPM1 gene cause cytoplasmic dislocation of the NPM1 protein. ${ }^{60}$ As a result, cytoplasmic NPM1 is unable to undertake its normal functions as binding and transporter protein. In CN-AML, NPM1 mutations without FLT3-ITD59 or a low allelic ratio are a more favourable prognostic factor. ${ }^{42}$

The prognostic effect of concurrent FLT3 and NPM1 mutations is a matter of controversy. A cohort study of young adult AML patients identified three prognostic groups: good (FLT3-ITD[-]NPM1[+]); intermediate (FLT3ITD[-]NPM1[-] or FLT3-ITD[+]NPM1[+]) and poor (FLT3-ITD[+]NPM1[-]). The authors concluded that patients with an FLT3-ITD mutation burden greater than $50 \%$ or (FLT3-ITD[+]NPM1[-]) have a poor prognosis and may be good candidates for experimental therapeutic approaches. ${ }^{61}$ However, another study found that the FLT3-ITD load also has to be taken into account: in patients with a high FLT3-ITD allelic burden, the effect of an NPM1 was less important..$^{62} \mathrm{~A}$ study of older AML patients suggested that NPM1(+)/FLT3-ITD-(-) confers a favourable prognosis for patients with AML of ages $55-65$ years but not in those of age $>65$ years. ${ }^{63}$ Recent recommendations from the ELN include a revised version of the risk stratification according to genetics including the allelic ratio (Table 1). ${ }^{3}$

\section{Detection of minimal residual disease}

Pretherapeutic molecular testing for NPM1 and FLT3 is considered a standard of care to determine the best treatment option. Whereas NPM1 has been shown to be a reliable marker for minimal residual disease (MRD) detection with high sensitivity, ${ }_{1}^{6466}$ the suitability of FLT3-ITD for MRD detection has been questioned. First, FLT3-ITD mutations display substantial heterogeneity in terms of size, number of clones per patient, allelic ratio and insertion site within the FLT3 gene and second, its proposed instability (reported on about $25 \%$ of paired diagnosis-relapse samples) during the course of treatment.
Current methods used to determine FLT3-ITD mutations have limited sensitivity and are not suitable for MRD detection. Newer techniques, such as real-time quantitative polymerase chain reaction (RT-qPCR) with patient-specific primers, aim to improve the sensitivity of FLT3-ITD.67 However, this approach has limitations, since each FLT3-ITD mutation needs a clone-specific primer/probe set, which is time-consuming and may not be possible in every case. In addition, direct sequencing may not be possible in patients with a low allelic ratio since the wild-type sequence is competitively amplified. Recently, another PCR-based assay for FLT3-ITD MRD was reported. ${ }^{68,69}$ This assay employed primers oriented in the opposite direction; hence, amplification occurred only if an FLT3-ITD was present. Again, this approach has limitations, since short FLT3-ITDS (less than 30-40 bases) are not detected due to insufficient primer annealing space, which may apply to roughly $25 \%$ of all FLT3-ITD cases. Both approaches are therefore not ready to be implemented in clinical routine care. Next-generation sequencing (NGS) is potentially useful70 but generates complex data which is still expensive and requires considerable expertise to interpret.

Nevertheless, in those patients with a concurrent NPM1 mutation, MRD can be assessed by analysis of NPM1 mutated transcripts. ${ }^{66}$

In summary, FLT3 mutational testing should be mandatory in all AML patients at diagnosis as well as at relapse for prognostic purposes and for guiding therapeutic decisions. At present, it has little utility for MRD monitoring until different methodologies can be standardised.

\section{Treatment options for FLT3-ITD acute myeloid leukaemia}

In younger patients with newly diagnosed AML considered suitable for intensive induction therapy, the combination of an anthracycline and cytarabine (" $7+3$ " regimen) remains the standard of care also for patients with activating FLT3 mutations. ${ }^{71}$ However, higher allelic ratios were associated with lower CR-rates after induction therapy ${ }^{42}$ bringing up the question of dose-intensification in these patients. ${ }^{72,73}$ In older adults a substantial proportion of patients cannot tolerate intensive induction chemotherapy; in these cases other less intensive regimens may be used including low-dose cytarabine ${ }^{74}$ or hypomethylating agents (e.g., azacitidine or decitabine). ${ }^{75,76}$ Based on the assessment of the risk-benefit ratio (i.e., non-relapse mortality/morbidity versus reduction of relapse risk) allo HSCT from matched-related or unrelated donor in early first $C R$ is the treatment option for patients with intermediate and adverse risk genetics. In addition, allo HSCT has been shown to improve outcomes in FLT3-ITD AML, particularly in patients with a high allelic ratio. ${ }^{.79}$ Nevertheless, recent studies indicate that AML patients with NPM1 mutation and low FLT3-ITD allelic ratio may have a more favourable prognosis and should therefore not routinely be assigned to allo HSCT. 42,43,80 In contrast, an ITD insertion site in the TKD1 remained an unfavourable prognostic factor regardless of the applied therapy. ${ }^{42}$ Another important prognostic factor has been shown for the NPM1 MRD status after the second chemotherapy ${ }^{66}$ or before allo HSCT. ${ }^{6,81}$

\section{New therapies targeting FLT3}

In the last decade, numerous small molecule FLT3-TKIs have been developed to disrupt oncogenic signalling. Most compete for the ATP binding site in the active domain of the kinase, inhibiting protein phosphorylation. ${ }^{82}$

Early TKIS, rather than being specifically designed to target FLT3, had multiple targets including KIT, PDGFR, VEGFR and JAK2. ${ }^{83}$ Several agents have shown evidence of modest antileukemic activity as monotherapy 
including midostaurin (phase IIb), ${ }_{1}^{84}$ linifanib (phase I), ${ }_{1}^{85}$ semaxanib (phase 11) $)^{86,87}$ tandutinib ${ }^{88}$ and KW-2449 (preclinical). ${ }^{89}$ However, responses were typically short-lived and mostly partial remissions.

Moreover, it has been suggested that the responsiveness to FLT3 TKIS seems to depend on the FLT3 allelic ratio. ${ }^{46}$ In an in vitro analysis, six different FLT3 inhibitors (lestaurtinib, midostaurin, AC220, KW-2449, sorafenib and sunitinib) were examined for potency against mutant and wild-type FLT3, as well as for cytotoxic effect against a series of primary blast samples obtained from FLT3-ITD mutated AML patients. Relapsed samples and samples with a high allelic ratio were more likely to be responsive to cytotoxicity from FLT3 inhibition as compared to the samples obtained at diagnosis or those with a low allelic ratio. ${ }^{46}$ Therefore, it has been hypothesised that patients with newly diagnosed FLT3-mutant AML might be less likely to respond to highly selective FLT3 inhibition. ${ }^{46}$ However, the results probably indicate that the presence of an FLT3-ITD with even a low allelic ratio cannot be excluded altogether from prognostic risk stratification.

\section{Results of clinical trials with tyrosine kinase inhibitor treatment}

The major clinical studies investigating TKI treatment in FLT3-mutated AML are summarised in Table 2. In a phase I/II study, monotherapy with lestaurtinib demonstrated biologic and clinical activity in five out of 14 heavily pretreated patients with relapsed or refractory FLT3mutated AML, including reductions of blast cells from bone marrow and peripheral blood..$^{90}$ In addition, in a phase II trial, single agent lestaurtinib has shown modest activity as first-line treatment for older AML patients who were unfit for intensive chemotherapy. Within this trial, lestaurtinib was given orally for 8 weeks, starting with $60 \mathrm{mg}$ twice daily (bid), escalating to $80 \mathrm{mg}$ bid, and was generally well tolerated. Clinical activity included transient reductions in bone marrow and peripheral blast cells in three of five patients with mutated FLT3 and five of 22 evaluable wild-type FLT3 patients. ${ }^{91}$ In both studies, FLT3 inhibition correlated with clinical response. These findings prompted a large, multicentre phase III clinical trial evaluating lestaurtinib in combination with chemotherapy in relapsed/refractory patients. However, no increase in response rates or prolongation of survival of AML patients with activating FLT3 mutations was found. ${ }^{92,93}$ In addition, it has been shown that plasma FLT3 ligand levels rise dramatically after chemotherapy and this has been suggested to interfere with the bioavailability of FLT3 TKIS.94 This issue has been evaluated in a meta-analysis of two consecutive phase III trials of the Medical Research Council (AML15 and AML17 trials), including $n=500$ FLT3-mutated AML patients. Within this trial, newly diagnosed AML patients with activating FLT3 mutations (median age, 49 years; range 5-68 years) were randomised to receive either oral lestaurtinib or placebo, for up to 28 days after each of the four courses of chemotherapy. ${ }^{95}$ Recently published data showed that lestaurtinib yielded no improvements in 5-year RFS and OS when added to first-line chemotherapy. ${ }^{95}$ Nevertheless, subgroup analysis indicated improved OS and significantly reduced rates of relapse in lestaurtinib-treated patients who sustained $>85 \%$ FLT3 inhibition as assessed by the plasma inhibitory activity assay. ${ }^{95}$ In addition, elevated FLT3 ligand had no impact on lestaurtinib plus chemotherapy treatment.95

Three multitargeted TKIs currently approved for other malignancies have demonstrated activity against FLT3: ponatinib, sunitinib and sorafenib. In a phase I study of 12 previously treated patients with AML (58\% had FLT3ITD), ponatinib gave an overall response rate (ORR) of $25 \% .{ }^{96}$ Following safety concerns, ponatinib was temporarily removed from the market in 2013. ${ }^{97}$ Since December 2013 the FDA has granted ponatinib full approval for the treatment of adult patients with chronic phase, accelerated phase or blast phase chronic myeloid leukaemia (CML) or t(9;22)-positive acute lymphoblastic leukaemia (ALL) for whom no other TKI therapy is indicated; and for the treatment of adult patients with T315I-positive CML or T315I-positive and t(9;22)-positive ALL. The full approval and label update was based on a 48-month follow-up data from the pivotal phase II PACE clinical trial of ponatinib in heavily pretreated patients with resistant or intolerant CML or $\mathrm{t}(9 ; 22)$-positive ALL. ${ }^{9.99}$ Currently, a dose escalation study of ponatinib, alone and in combination with 5-azacytidine, in patients with FLT3-mutated AML is planned at the MD Anderson Center but not yet recruiting. ${ }^{100}$ In addition, sunitinib in combination with intensive chemotherapy (cytosine arabinoside/daunorubicin induction followed by three cycles of intermediate-dose cytosine arabinoside) as maintenance therapy for 2 years showed promising findings in a phase I/ II trial of 22 AML patients with activating FLT3 mutations. ${ }^{101}$

Sorafenib demonstrated efficacy in phase I studies, and no dose-limiting toxicity was observed. ${ }^{102,103}$ The addition of sorafenib to chemotherapy has also yielded positive data in a phase I and II study. ${ }^{104,05}$ In the phase II study in younger adult (age range, 18-60 years) AML patients ( $n=267$, of whom $n=46$ were positive for FLT3-ITD), median EFS was 9 months in the placebo group as compared to 21 months in the sorafenib group, corresponding to a 3-year EFS of 22\% in the placebo group as compared to $40 \%$ in the sorafenib group (HR $0.64,95 \%$ confidence interval $[\mathrm{Cl}]$; $0.45-0.91 ; \mathrm{p}=0.013) .{ }^{104}$ In the subgroup analysis of FLT3-ITD positive AML, RFS (18 versus 6 months) and OS (not reached versus 19 months) were higher in the sorafenib group as compared to the placebo group.

The results in elderly AML patients with sorafenib in combination with standard intensive chemotherapy are controversial. Whereas one randomised double-blinded study in 197 elderly AML patients found no beneficial effect of the addition of sorafenib as compared to placebo, 106 the opposite was the case in a recently published trial. ${ }^{107}$ Within this study, sorafenib was added to daunorubicin and cytarabine-based induction and consolidation chemotherapy and was also continued for 12 months of maintenance therapy. Fifty-four patients with a median age of 67 years (range, 60-83 years) were enrolled ( $n=39$ were FLT3-ITD mutated (71\%) and $\mathrm{n}=15$ were FLT3-TKD (29\%) mutated). The observed 1-year OS was $62 \%(95 \%-\mathrm{Cl}, 45-78 \%)$ for the FLT3-ITD patients (meeting the primary end point $62 \%$ versus $30 \%$ for a historical control group, $p<0.0001$ ) and $71 \%$ (95\%-Cl, 42-92\%) for the FLT3-TKD patients. Nevertheless, the study by Serve et al. ${ }^{106}$ might have been biased, since the trial was not selected for the target population and the proportion of FLT3-ITD was very low in the study cohort (28 of 197 patients; 14\%). In a phase II study of previously treated patients with AML ( $n=37$, FLT3-ITD in 93\%), a lower intensity regime with azacytidine yielded promising results: an ORR for response of $46 \%$ including incomplete count recovery (CRi) in $27 \%$, CR in $16 \%$ and partial response (PR) in $3 \%$. The median time to achieve CR/CRi was two cycles and the median duration of CR/CRi was 2.3 months. ${ }^{108}$ These findings suggest that further investigation of sunitinib and sorafenib in this treatment setting is warranted.

Midostaurin is currently the only TKI that has demonstrated convincingly superior results as compared to standard intensive therapy in younger FLT3-mutated AML patients for all survival end points including OS. ${ }^{109}$ Midostaurin affects multiple targets including c-Kit, platelet-derived growth factor receptors (PDGFR), as well as FLT3. ${ }^{1{ }^{10}}$ In a phase I-II trial midostaurin $50 \mathrm{mg}$ orally $2 \times$ /day given for 14 days was safely combined with standard induction therapy of daunorubicin and cytarabine in patients with newly diagnosed AML and a CR-rate of $80 \%$ could be achieved. ${ }^{111}$ These encouraging results provided rationale to move on to a randomised 
Table 2: Clinical studies of tyrosine kinase inhibitors (phase I-III)

\begin{tabular}{|c|c|c|c|}
\hline Agent & Study type & Outcomes & Reference \\
\hline Crenolanib & $\begin{array}{l}\text { Phase } \|, n=34 \text {, heavily pretreated relapsed/ } \\
\text { refractory patients, median duration } 9 \text { weeks. }\end{array}$ & $\begin{array}{l}\text { ORR }=47 \% \text {. Median EFS was } 8 \text { weeks and OS was } 19 \text { weeks for the whole } \\
\text { cohort. Well-tolerated. }\end{array}$ & $\begin{array}{l}\text { Randhawa et al., } \\
2014^{122}\end{array}$ \\
\hline $\begin{array}{l}\text { Gilteritinib } \\
\text { (ASP2215) }\end{array}$ & $\begin{array}{l}\text { Phase } \mathrm{I} / \mathrm{II}, \mathrm{n}=215 \text {, relapsed or refractory } \mathrm{AML}, 65 \% \\
\text { received } \geq 2 \text { prior lines of AML therapy, } 29 \% \text { had } \\
\text { prior HSCT and } 23 \% \text { had prior TKI. }\end{array}$ & $\begin{array}{l}\text { ORR }=52 \% \text { with CR in } 11 \% \text {. Treatment-related AEs of all grades, reported } \\
\text { in } \geq 10 \% \text { of the safety population were diarrhoea (16\%), fatigue (13\%) and } \\
\text { increased AST (11\%). }\end{array}$ & $\begin{array}{l}\text { Perl et al., } \\
2016^{125}\end{array}$ \\
\hline Lestaurtinib & $\begin{array}{l}\text { Phase } I I, n=29, \text { newly diagnosed AML, age }>70 \\
\text { years (or 60-70 years with comorbidity). }\end{array}$ & $\begin{array}{l}\text { Clinical activity (transient reductions in bone marrow and peripheral-blood } \\
\text { blasts or longer periods of transfusion independence) in } 60 \% \text { of patients with } \\
\text { mutated FLT3 and } 23 \% \text { of wild-type FLT3 patients. }\end{array}$ & $\begin{array}{l}\text { Knapper et al., } \\
2006^{91}\end{array}$ \\
\hline Lestaurtinib & $\begin{array}{l}\text { Phase III, } n=500 \text {, newly diagnosed } A M L \text {, duration } \\
5 \text { years. }\end{array}$ & No difference in CR, RFS or OS between the arms. & $\begin{array}{l}\text { Knapper et al., } \\
2014^{92}\end{array}$ \\
\hline Midostaurin & Phase $\mathrm{Ib}, \mathrm{n}=20$, relapsed/refractory AML. & PB blasts $<50 \%$ : in $70 \%$ of patients; BM blasts $<50 \%$ : in $30 \%$ of patients. & $\begin{array}{l}\text { Stone et } \\
\text { al.,2012 } 2111\end{array}$ \\
\hline $\begin{array}{l}\text { Midostaurin + } \\
\text { chemotherapy }\end{array}$ & $\begin{array}{l}\text { Phase III, } \mathrm{n}=717 \text {, previously untreated } \mathrm{AML} \text {, } \\
\text { median follow-up } 57 \text { months. }\end{array}$ & $\begin{array}{l}\text { CR in } 59 \% \text { versus } 54 \% \text { placebo, } p=0.18 \text {; median OS=74.7 months versus } \\
26.0 \% \text {. EFS } 8 \text { months versus } 3 \text { months. No difference in AEs between two } \\
\text { groups. }\end{array}$ & $\begin{array}{l}\text { Stone et al., } \\
2015^{112}\end{array}$ \\
\hline $\begin{array}{l}\text { Sorafenib }+ \\
\text { chemotherapy }\end{array}$ & $\begin{array}{l}\text { Phase } I I, n=276 \text {, previously untreated AML, median } \\
\text { follow-up } 36 \text { months. }\end{array}$ & $\begin{array}{l}\text { Median EFS=21 months versus } 9 \text { months in placebo group. Grade } \geq 3 \text { AEs } \\
\text { that were significantly more common in the sorafenib group than the } \\
\text { placebo group were fever (RR 1.54), diarrhoea (RR 7.89), bleeding (RR 3.75, } \\
\text { 1.5-10.0), cardiac events (RR 3.46), hand-foot-skin reaction (only in sorafenib } \\
\text { group), and rash (RR 4.06). }\end{array}$ & $\begin{array}{l}\text { Röllig et al., } \\
2015^{104}\end{array}$ \\
\hline Sorafenib & $\begin{array}{l}\text { Phase } \|, n=197, \text { newly diagnosed AML, age }>60 \\
\text { years. }\end{array}$ & $\begin{array}{l}\mathrm{CR} \text { in } 48 \% \text { with sorafenib, } 60 \% \text { with placebo, no difference in EFS or OS } \\
\text { between placebo and sorafenib treatment cohort. }\end{array}$ & $\begin{array}{l}\text { Serve et al., } \\
2013^{106}\end{array}$ \\
\hline $\begin{array}{l}\text { Sunitinib + } \\
\text { chemotherapy }\end{array}$ & Phase $\mathrm{I} / \mathrm{II}$, age $>60$ years, $\mathrm{n}=22$, duration 2 years. & $\begin{array}{l}\mathrm{CR} \text { in } 59 \% \text {. At lower dose, median OS and EFS were 1.6, and } 0.4 \text { years, } \\
\text { respectively. Dose-limiting toxicities at higher dose. }\end{array}$ & Fiedler, $2015^{101}$ \\
\hline $\begin{array}{l}\text { Tandutinib } \\
\text { (MLN-518) }\end{array}$ & Phase $\|, n=20$, relapsed/refractory AML. & No $\mathrm{CR}$ or $\mathrm{PR}$, antileukemic effect in $30 \%$. & $\begin{array}{l}\text { DeAngelo et al., } \\
2006^{88}\end{array}$ \\
\hline $\begin{array}{l}\text { Quizartinib } \\
\text { (AC220) }\end{array}$ & $\begin{array}{l}\text { Phase II, } n=137 \text {, relapsed or refractory to second- } \\
\text { line, salvage chemotherapy or relapsed after HSCT. }\end{array}$ & $\begin{array}{l}\text { CT rate } 44 \% \text { with median duration of response of } 11.3 \text { weeks and median } \\
\text { OS of } 23.1 \text { weeks. Most common AEs were nausea (38\%), anaemia (29\%), } \\
\text { QT interval prolongation ( } 26 \%) \text {, vomiting ( } 26 \%) \text {, febrile neutropenia (25\%), } \\
\text { diarrhoea (20\%) and fatigue (20\%). Most common Grade } 3 \text { or } 4 \text { AEs were } \\
\text { anaemia ( } 26 \%) \text {, febrile neutropenia ( } 25 \%) \text {, thrombocytopenia diarrhoea, } \\
\text { neutropenia (12\%) and QT interval prolongation (10\%). }\end{array}$ & $\begin{array}{l}\text { Levis et al., } \\
2012^{119}\end{array}$ \\
\hline $\begin{array}{l}\text { Quizartinib } \\
\text { (AC220) }\end{array}$ & $\begin{array}{l}\text { Phase } \|, n=76 \text {, relapsed or refractory AML after } \\
\text { either one second-line therapy or HSCT, median } \\
\text { treatment duration } 10.9 \text { weeks Group A ( } 30 \text { mg/ } \\
\text { day) and } 11.0 \text { weeks Group B ( } 60 \text { mg/day). }\end{array}$ & $\begin{array}{l}\text { CR rate in both groups=47\%; ORR=61\% in Group A and } 71 \% \text { in Group B. } \\
\text { Median OS was } 20.7 \text { weeks in Group A and } 25.4 \text { weeks in Group B. AEs: } \\
\text { diarrhoea (18\%), febrile neutropenia (16\%) and QT prolongation (15\%). }\end{array}$ & $\begin{array}{l}\text { Schiller et al., } \\
2014^{120}\end{array}$ \\
\hline
\end{tabular}

AES = adverse events; $A M L=$ acute myeloid leukaemia; $A S T=$ aspartate aminotransferase; $C R=$ complete response; $E F S=$ event-free survival; $H S C T=$ haematopoietic stem cell transplantation; $O R R=$ overall response rate; $O S=$ overall survival; $P R=$ partial response; $R F S=$ relapse-free survival; $R R=$ relative risk; $T K I=$ tyrosine kinase inhibitor.

phase III trial CALGB 10603 (RATIFY; NCT00651261). The trial was activated in May 2008 and recruitment of over 700 younger adult FLT3mutated, including FLT3-ITD and FLT3-TKD, AML patients (18-59 years) was finally achieved in October 2011. The study scheme consisted of the addition of midostaurin or placebo to standard intensive "7+3" induction chemotherapy as well as four cycles of high-dose cytarabine (HIDAC) as consolidation therapy. In all patients, maintenance therapy of 1 year with midostaurin or placebo according to initial randomisation was intended. Although not specifically mandated, allo HSCT was performed in $57 \%$ of the overall study cohort including transplants in refractory and relapsed patients. The combination of midostaurin to intensive chemotherapy significantly improved OS in younger adults with FLT3-mutated AML with a HR of 0.77 (95\%-Cl: 0.63-0.95, $p=0.008$ ), translating into a median OS of 74.7 months for the midostaurin arm (range, 31.7 months - not reached) as compared to 25.6 months for the placebo-arm (range, 18.6-42.9 months), respectively. Interestingly, this improvement was regardless of the FLT3 mutational status (either ITD or TKD) or the FLT3-ITD allelic ratio. ${ }^{12}$ Based on these results, on April 28, 2017, the US Food and Drug Administration (FDA) approved midostaurin
(Rydapt ${ }^{\circledR}$; Novartis; Basel, Switzerland) for the treatment of AML in newly diagnosed patients who are FLT3-mutation-positive as detected by an FDA-approved test, in combination with chemotherapy. ${ }^{113}$ In Europe, the marketing authorisation application for midostaurin is still under review by the European Medicines Agency (EMA). Based on a phase II followup study of the RATIFY trial in AML patients (age 18-70 years) with FLT3ITD evaluating midostaurin in combination with intensive induction-, consolidation- including allo HSCT and maintenance therapy in all patients, the approval may be extended to older patients aged between 60 and 70 years. ${ }^{114}$

In addition, the combination of sequential azacitidine (intravenous $75 \mathrm{mg} / \mathrm{m}^{2}$ daily for 7 days) and escalating doses of oral midostaurin $(25,50$ and $75 \mathrm{mg}$ bid) on days 8-21 of a 28-day cycle has been investigated in a phase I study in untreated, elderly (median age: 73, range 57-83 years) and/or relapsed AML patients. No doselimiting toxicities occurred. Seventeen patients were enrolled and 14 patients were evaluable for response: three attained a CR and two had haematologic improvement. Median survival from enrolment 
was 6 months (range, 1 to $\geq 19$ months). Interestingly, none of the patients harboured an FLT3 mutation. The authors concluded that the combination of sequential azacitidine and midostaurin was safe and tolerable with response rates comparable with azacitidine alone. ${ }^{115}$

The combination therapy of midostaurin and azacitidine was also evaluated in a phase I/II study ( $n=54 ; 74 \%$ had a FLT3 mutation; $76 \%$ had been previously treated). During the dose-finding part of the study, six patients received midostaurin at a dose of $25 \mathrm{mg}$ bid and eight at a dose of $50 \mathrm{mg}$ bid. No dose-limiting toxicities occurred. Among the 54 patients in the phase II study, after a median of 12 weeks (range, 1-31), the ORR was $26 \%$. One patient (2\%) achieved a CR, six (11\%) achieved a CR with CRi, six (11\%) a morphologic leukaemia-free status (defined as $<5 \%$ blasts in the bone marrow regardless of neutrophil and platelet count in the peripheral blood) and one patient (2\%) a PR. ${ }^{115,116}$ Nevertheless, even with the addition of midostaurin to intensive therapy including allo HSCT and maintenance therapy within the RATIFY trial, a significant proportion of the patients still relapsed within the first 2 years, ${ }^{112}$ raising the question as to whether or not more selective TKIs would be more beneficial.

Second-generation FLT3 TKIs including quizartinib, crenolanib, PLX3397 and gilteritinib (formerly ASP2215), are more potent and selective based on cell cultures and animal models than the first-generation inhibitors. ${ }^{17}$ Quizartinib, a novel bis-aryl urea, is very specific for FLT3, has a high capacity for sustained FLT3 inhibition and an acceptable toxicity profile. ${ }^{118}$ In a phase II study quizartinib demonstrated particular efficacy in patients with FLT3-ITD mutations $(n=137)$ who were relapsed or refractory to second-line, salvage chemotherapy or relapsed after allo HSCT. ${ }^{119}$ The CR rate was $44 \%$ with a median duration of response of 11.3 weeks and median OS of 23.1 weeks. Of note, one-third of patients were successfully bridged to allo HSCT. A subsequent phase II study recruited 76 patients with FLT3-ITD mutations, with relapsed or refractory AML after either one second-line therapy or allo HSCT. Patients were randomised to quizartinib 30 mg/day (Group A) or 60 mg/day (Group B) given orally during 28-day continuous treatment cycles, until relapse, intolerance or proceeding to allo HSCT. The ORR was 61\% in Group A and 71\% in Group B. In addition, $32 \%$ of patients in Group A and $42 \%$ in Group B could be successfully bridged to allo HSCT. ${ }^{120} \mathrm{~A}$ phase III study of quizartinib or placebo with induction and consolidation chemotherapy, and as maintenance in patients with newly diagnosed FLT3-ITD AML, is ongoing (age range: 1875 years, planned inclusion number: $n=536$; ClincalTrials.gov identifier: NCT02668653). ${ }^{121}$ However, resistance to quizartinib in FLT3-TD has been reported; this has been attributed to acquired D835Y TKD mutation on the FLT3-ITD allele. ${ }^{57}$

Other second-generation FLT3 inhibitors have also yielded positive findings. Gilteritinib and crenolanib are able to inhibit both FLT3-ITD and FLT3-TKD mutations. High response rates have been reported in two clinical studies of crenolanib, particularly in FLT3 inhibitor-naive patients (phase II). ${ }^{12,123}$ In a single centre phase $\|$ study $(n=34)$, patients had received a median of 3.5 prior therapies (sorafenib in $57 \%$, quizartinib in $14 \%$, PLX3397 in 5\% and midostaurin in 10\%; $9 \%$ and $5 \%$ had received two and three FLT3 TKIs, respectively). At a median follow-up of 14 weeks, the ORR was $47 \%$ : $12 \%$ achieved CRi, and $3 \%$ morphologic leukaemia-free state. The median EFS was 8 weeks and OS was 19 weeks for the whole cohort. ${ }^{122}$ In another phase II study of relapsed/refractory patients ( $n=19$, median age 47 years), one patient had a CR while two had a CRi and four patients were bridged to transplant. ${ }^{23}$ These preliminary data suggest that crenolanib is very promising in relapsed and refractory AML patients, and further trials are being initiated (e.g., NCT02298166, NCT02400281, NCT02270788, NCT02283177).
In a phase $1 /$ II study ( $\mathrm{n}=252)$ of heavily pretreated patients $(70 \%$ had $\geq 2$ prior AML therapies, $29 \%$ had prior HSCT, and 25\% had prior TKI treatment, most commonly sorafenib) receiving gilteritinib, FLT3-ITD patients showed an ORR of $52 \%$, with CR in $11 \%$. Clinical responses occurred in FLT3-mutated patients with ITD, D835 and both mutations (ORR: 55\%, $17 \%$ and $62 \%$, respectively). The median OS for FLT3-mutated patients receiving gilteritinib $\geq 80 \mathrm{mg}$ was around 31 weeks. ${ }^{24} \mathrm{~A}$ phase III trial of gilteritinib is currently ongoing (NCT02421939, estimated enrolment 369). Patients with FLT3-mutated AML in first relapse or refractory to frontline therapy are being recruited and randomised to treatment with either gilteritinib or to investigator's prerandomisation choice of specified salvage chemotherapy. The primary objective is OS; key secondary objectives are EFS and CR rate. ${ }^{125}$

\section{TKI treatment postallogeneic HSCT}

In addition, the efficacy of TKIs following allo HSCT is being investigated. A retrospective multicentre study of 29 patients who had undergone allo HSCT, treatment with sorafenib led to haematological remission in 37\%, bone marrow remission in $8 \%, C R$ (with and without normalisation of peripheral blood counts) in $23 \%$ and molecular remission with undetectable FLT3-ITD MRNA in 15\%, respectively. Allo HSCT patients developed sorafenib resistance less frequently (38\% versus $47 \%$ ) and significantly later (197 days versus 136 days, $\mathrm{p}=0.03$ ) than those without prior HSCT, and sustained remissions were seen only in the allo HSCT cohort. ${ }^{102}$ The addition of midostaurin to intensive induction therapy and as maintenance after allo HSCT or HiDAC is currently being investigated. Preliminary data indicate that this approach was feasible and outcomes were favourable compared with historical data, particularly in patients with a high FLT3-ITD mutant to wild type ratio. ${ }^{114} \mathrm{An}$ ongoing trial is also investigating the efficacy and safety of quizartinib, postallogeneic transplant (NCT02668653). ${ }^{121}$

\section{Mechanisms of resistance}

Patients who relapse after treatment with a TKI can develop point mutations in the target kinase domain as a mechanism of resistance. 57, 126 Resistance has also been associated with upregulation of parallel and downstream signal transduction pathways, and may also involve stromal cells of the bone marrow. ${ }^{27}$ In addition, an interaction between CD34+ progenitor cells from patients with FLT3-ITD mutations and niche cells has been reported in another publication. ${ }^{28}$ This interaction enables the maintenance of leukemic progenitors in the presence of a TKI. ${ }^{128}$

Different FLT3 TKIs display distinct and nonoverlapping resistance profiles in vitro; TKD1 mutations showed a response to SU5614, sorafenib and sunitinib but diminished response to PKC412, whereas TKD2 mutations were sensitive to PKC412, sunitinib or sorafenib. ${ }^{56}$

Another mechanism of resistance might be related to the FLT3-ITD insertion site. ${ }^{129}$ These data suggest that combinations of FLT3 inhibitors may be required to prevent FLT3 resistance mutations in FLT3-ITDpositive AML. Some research has suggested that FLT3 inhibitor therapy combined with crenolanib may prevent the emergence of resistance. ${ }^{49}$

\section{Future developments}

Targeting multiple pathways may be necessary to ensure enduring responses, leading to a focus on combined treatment regimens. A phase I clinical trial evaluating the combination of the mammalian target of rapamycin (mTOR)-inhibitor RAD001 with midostaurin is ongoing. ${ }^{130}$ Homoharringtonine has been shown to act synergistically with FLT3 inhibitors. ${ }^{131}$ In addition, preclinical data suggest that a number of PI3K, AKT, mTOR and MEK inhibitors may act synergistically with FLT3 inhibition. ${ }^{122-134}$ Recently, dual inhibition of FLT3 and Pim kinases has been found to 
eradicate FLT3-ITD mutated AML cells in vitro. ${ }^{135}$ However, concern has been expressed that targeting multiple pathways may result in increased toxicity; therefore, more clinical data are needed on these combinations.

Other multitargeted TKIs are also in early stage clinical development. Pacritinib (formerly SB1518) is a TKI with activity against FLT3 and Janus kinase $2 .{ }^{136}$ The first clinical study of pacritinib showed promising results. ${ }^{137}$

\section{Summary and concluding remarks}

Increased understanding of FLT3 mutations in AML has presented an opportunity for the use of targeted therapies, and thus broadened a treatment landscape that has remained unchanged for decades. The incorporation of FLT3 TKIs into current treatment paradigms should lead to a significant improvement in the prognosis for AML patients with activating FLT3 mutations. Of the several promising therapeutic agents that are in clinical development, midostaurin is at the most advanced stage and is the first targeted agent to improve survival in AML with FLT3 mutations in combination with intensive chemotherapy and/or allo
HSCT including maintenance therapy in younger, adult AML with FLT3mutations. Since midostaurin was FDA approved on April 28, 2017, its use according to the CALGB 10603/RATIFY trial to treat younger adult AML patients with FLT3-mutations seems currently to be the best approach for this patient group. Whether newer, more selective TKIs might be clinically more beneficial is currently being tested in clinical trials.

The optimum use of FLT3 TKIs remains an active area of research. Numerous questions remain unanswered, including the optimal sequencing of second-generation FLT3-specific agents and multikinase TKIs. Complete and sustained inhibition of FLT3-mutated AML may require a combination of agents, both targeted and conventional chemotherapy, but at present the optimal schedule is not known. The optimum role of FLT3 TKIs in relapsed/refractory patients as a bridge to allo HSCT or as post-HSCT maintenance remains to be established. There is a need for further randomised clinical trials to investigate these questions. Further research will expand our understanding of FLT3 mutations and the mechanisms of resistance to FLT3 TKIs. $\square$
1. Juliusson $G$, Antunovic $P$, Derolf $A$, et al., Age and acute myeloid leukemia: real world data on decision to treat and outcomes from the Swedish Acute Leukemia Registry, Blood, 2009;113:4179-87

2. Schlenk RF, Dohner $\mathrm{H}$, Genomic applications in the clinic: use in treatment paradigm of acute myeloid leukemia, Hematology Am Soc Hematol Educ Program, 2013;2013:324-30.

3. Dohner $H$, Estey E, Grimwade D, et al., Diagnosis and management of AML in adults: 2017 ELN recommendations from an international expert panel, Blood, 2017;129:424-47.

4. Breems DA, Van Putten WL, De Greef GE, et al., Monosomal karyotype in acute myeloid leukemia: a better indicator of poor prognosis than a complex karyotype, I Clin Oncol, 2008;26:4791-7.

5. Haferlach C, Dicker F, Herholz $\mathrm{H}$, et al., Mutations of the TP53 gene in acute myeloid leukemia are strongly associated with a complex aberrant karyotype, Leukemia, 2008;22:1539-41.

6. Bowen D, Groves MJ, Burnett AK, et al., TP53 gene mutation is frequent in patients with acute myeloid leukemia and complex karyotype, and is associated with very poor prognosis, Leukemia, 2009;23:203-6.

7. Rucker FG, Schlenk RF, Bullinger L, et al., TP53 alterations in acute myeloid leukemia with complex karyotype correlate with specific copy number alterations, monosomal karyotype, and dismal outcome, Blood, 2012;119:2114-21.

8. Papaemmanuil E, Gerstung M, Bullinger $L$, et al., Genomic classification and prognosis in acute myeloid leukemia, N Engl I Med, 2016;374:2209-21.

9. Roboz GJ, Current treatment of acute myeloid leukemia, Curr Opin Oncol, 2012;24:711-9

10. U.S. Department of Health and Human Services archive page, FDA Approves All-Trans Retinoic Acid for Treating a Rare Leukemia. Available at: http://archive.hhs.gov/new press/1995pres/951128a.html (accessed 1 July 2016). . Antman KH, Introduction: the history of arsenic trioxide in cancer therapy, Oncologist, 2001;6 Suppl 2:1-2.

12. Yamamoto JF, Goodman MT, Patterns of leukemia incidence in the United States by subtype and demographic characteristics, 1997-2002, Cancer Causes Control, 2008;19:379-90.

13. Ley TJ, Miller C, Ding L, et al., Genomic and epigenomic
landscapes of adult de novo acute myeloid leukemia, N Eng/J landscapes of adult de $n$

14. Moreno I, Martin G, Bolufer P, et al., Incidence and prognostic value of FLT3 internal tandem duplication and D835 mutations in acute myeloid leukemia, Haematologica, 2003;88:19-24.

15. Stirewalt DL, Radich JP, The role of FLT3 in haem,
malignancies, Nat Rev Cancer, 2003;3:650-65.

malignancies, Nat Rev Cancer, 2003;3:650-65.
16. Hannum C, Culpepper J, Campbell D, et al., Ligand for FLT3/FLK receptor tyrosine kinase regulates growth of haematopoietic stem cells and is encoded by variant RNAs, Nature 1994;368:643-8

17. Griffith J, Black J, Faerman C, et al., The structural basis for autoinhibition of FLT3 by the juxtamembrane domain, Mol Cell, 2004:13:169-78.

18. Gu TL, Nardone J, Wang Y, et al., Survey of activated FLT3 signaling in leukemia, PLoS One, 2011;6:e19169.

19. Hayakawa F, Towatari M, Kiyoi H, et al., Tandem-duplicated Flt3 constitutively activates STATS and MAP Kinase and introdu

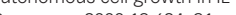
Oncogene, 2000,19:624-31.

20. Gilliand DG, Griffin JD, The roles of FLT3 in hematopoiesis and eukemia, Blood, 2002,100:1532-42.

0 , Marchetto S, deLapeyriere O, et al., Murine Flt3, a CSF encoding a nove ty

22. Meshinchi S, Appelbaum FR, Structural and functional alterations of FLT3 in acute myeloid leukemia, Clin Cancer Res, 2009:15:4263-9.

23. Kindler T, Lipka DB, Fischer T, FLT3 as a therapeutic target challenging after all these years, Blood, 2010;116:5089-102.
24. Schneider F, Hoster E, Schneider S, et al., Age-dependent frequencies of NPM1 mutations and FLT3-ITD in patients wit normal karyotype AML (NK-AML), Ann Hematol, 2012;91:9-18.

5. Frohling S, Schlenk RF, Breltruck J, et al., Prognostic significance of activating FLT3 mutations in younger adults (16 to 60 years) with acute myeloid leukemia and normal cytogenetics: a study of the AML Study Group UIm, Blood, 2002;100:4372-80.

26. Yanada M, Matsuo K, Suzuki T, et al., Prognostic significance of FLT3 internal tandem duplication and tyrosine kinase domain mutations for acute myeloid leukemia: a meta-analysis, Leukemia, 2005;19:1345-9.

27. Kiyoi H, Yanada M, Ozekia K, Clinical significance of FLT3 leukemia, Int J Hematol, 2005;82:85-92.

28. Fleischmann M, Schnetzke U, Schrenk KG, et al., Outcome of FLT3-ITD-positive acute myeloid leukemia: impact of allogeneic stem cell transplantation and tyrosine kinase inhibitor treatment, I Cancer Res Clin Oncol, 2017;143:337-45.

29. Chevallier P, Labopin M, Turlure P, et al., A new Leukemia Prognostic Scoring System for refractory/relapsed adult acute myelogeneous leukaemia patients: a GOELAMS study, Leukemia, 2011;25:939-44.

30. Wagner K, Damm F, Thol F, et al., FLT3-internal tandem duplication and age are the major prognostic factors in patient with relapsed acute myeloid leukemia with normal karyotype Haematologica, 2011;96:681-6.

31. Wattad M, Weber D, Dohner K, et al., Impact of salvage regimens on response and overall survival in acute myeloid leukemia with induction failure, Leukemia, 2017;31:1306-31

32. Schlenk RF, Frech P, Weber D, et al., Impact of pretreatment characteristics and salvage strategy on outcome in patients with relapsed acute myeloid leukemia, Leukemia 2017;31:1217-20.

33. Kayser S, Schlenk RF, Londono MC, et al., Insertion of FLT3 internal tandem duplication in the tyrosine kinase domain-1 is associated with resistance to chemotherapy and inferio outcome, Blood, 2009;114:2386-92

34. Schnittger S, Bacher U, Haferlach C, et al., Diversity of the juxtamembrane and TKD1 mutations (exons 13-15) in the FLT3 gene with regards to mutant load, sequence, length, Iocalization, and correlation with biological data, Genes Chromosomes Cancer, 2012;51:910-24.

35. Ponziani V, Gianfaldoni G, Mannelli F, et al., The size of duplication does not add to the prognostic significance of FLT3 internal tandem duplication in acute myeloid leukemia patients, Leukemia, 2006;20:2074-6.

36. Kusec $\mathrm{R}$, Jaksic $\mathrm{O}$, Ostojic $\mathrm{S}$, et al., More on prognostic significance of FLT3/TTD size in acute myeloid leukemia (AML), Blood, 2006;108:405-6; author reply 6.

37. Kim Y, Lee GD, Park J, et al., Quantitative fragment analysis of FLT3-ITD efficiently identifying poor prognostic group with high mutant all 2015;5:e336

8. Stirewalt DL, Kopecky KJ, Meshinchi S, et al., Size of FLT3 internal tandem duplication has prognostic significance in

patients with acute myeloid leukemia, Blood, 2006;107:3724-6. Blau 0 , Berensten $\mathrm{R}$, Sindram A, et al., Molecular analysis of different FLT3-ITD mutations in

40. Breitenbuecher F, Schnittger S, Grundler R, et al. Identification of a novel type of ITD mutations located in nonjuxtamembrane domains of the FLT3 tyrosine kinase receptor, Blood, 2009:113:4074-7.

41. Pratcorona M, Brunet $\mathrm{S}$, Nomdedeu J, et al., Favorable outcome of patients with acute myeloid leukemia harboring a low-allelic burden FLT3-ITD mutation and concomitant NPM1 mutation: relevance to post-remission therapy, Blood, 2013;121:2734-8.

2. Schlenk RF, Kayser S, Bullinger L, et al., Differential impact of allelic ratio and insertion site in FLT3-ITD-positive AML with

Gale RE, Green C, Allen C, et al. The , impact of FLT3 internal tandem duplication mutant level, number, size, and interaction with NPM1 mutations in a large cohort of young adult patients with acute myeloid leukemia, Blood, 2008;111:2776-84.

44. Thiede C, Steudel C, Mohr B, et al., Analysis of FLT3-activating mutations in 979 patients with acute myelogenous leukemia: association with FAB subtypes and identification of subgroups with poor prognosis, Blood, 2002;99:4326-35.

45. Kottaridis PD, Gale RE, Langabeer SE, et al., Studies of FLT3 mutations in paired presentation and relapse samples from patients with acute myeloid leukemia: implications for the role of FLT3 mutations in leukemogenesis, minimal residual disease detection, and possible therapy with FLT3 inhibitors, Blood, 2002;100:2393-8

46. Pratz KW, Sato T, Murphy KM, et al., FLT3-mutant allelic burden and clinical status are predictive of response to FLT3 inhibitor in AML, Blood, 2010;115:1425-32.

4. Warren M, Luthra R, Yin CC, et al., Clinical impact of change of FLT3 mutation status in acute myeloid leukemia patients, MOd Pathol, 2012;25:1405-12.

48. Yamamoto Y, Kiyoi H, Nakano Y, et al., Activating mutation of D835 within the activation loop of FLT3 in human hematologic malignancies, Blood, 2001;97:2434-9.

49. Zhang W, Gao C, Konopleva M, et al., Reversal of acquired drug resistance in FLT3-mutated acute myeloid leukemia cells via distinct drug combination strategies, Clin Cancer Res, 2014;20:2363-74

50. Mead AJ, Linch DC, Hills RK, et al., FLT3 tyrosine kinase domain mutations are biologically distinct from and have a significantly more favorable prognosis than FLT3 internal tandem duplications in patients with acute myeloid leukemia, Blood, 2007;110:1262-70

51. Whitman SP, Ruppert AS, Radmacher MD, et al., FLT3 D835//836 mutations are associated with poor disease-free survival and a distinct gene-expression signature among younger adults with de novo cytogenetically normal acute myeloid leukemia lacking FLT3 internal tandem duplications, Blood 2008; 111:1552-9.

52. Santos FP, Jones D, Qiao W, et al., Prognostic value of FLT3 mutations among different cytogenetic subgroups in acute myeloid leukemia, Cancer, 2011;117:2145-55.

53. Allen C, Hills RK, Lamb K, et al., The importance of relative mutant level for evaluating impact on outcome of KIT, FLT3 and CBL mutations in core-binding factor acute myeloid leukemia Leukemia, 2013;27:1891-901

54. Kok CH, Brown AL, Perugini M, et al., The preferential occurrence of FLT3-TKD mutations in inv(16) AML and impact on survival outcome: a combined analysis of 1053 core-binding factor AML patients, Br J Haematol, 2013;160:557-9.

55. Moore AS, Faisal A, Gonzalez de Castro D, et al., Selective FLT3 inhibition of FLT3-ITD+ acute myeloid leukaemia resulting in
secondary D835Y mutation: a model for emerging clinical secondary D835Y mutation: a model for emerging
resistance patterns, Leukemia, 2012;26:1462-70.

56. von Bubnoff N, Engh RA, Aberg E, et al., FMS-like tyrosine Von Bubnoff N, Engh RA, Aberg E, et al., FMS-like tyrosine
kinase 3-internal tandem duplication tyrosine kinase inhibitors display a nonoverlapping profile of resistance mutations in vitro, Cancer Res, 2009:69:3032-41.

57. Smith CC, Wang Q, Chin CS, et al., validation of ITD mutations in FLT3 as a therapeutic target in human acute myeloid leukaemia, Nature, 2012;485:260-3.

58. Thiede C, Koch S, Creutzig E, et al., Prevalence and prognostic impact of NPM1 mutations in 1485 adult patients with acute

myeloid Ieukenia (AML), Blood, 2006; 107:4011-20.

. Schlenk RF, Dohner K, Krauter J, et al., Mutations and treatment outcome in cytogenetically normal acte mi NEngl Med, 2008,358.1909-18.

6. Falini B, Mecucci C, Tiacci E, et al., Cytoplasmic nucleophosmin in acute myelogenous leukemia with a normal karyotype, NEng/ J Med, 2005;352:254-66,

. Gale RE, Green C, Allen C, et al., The impact of FLT3 internal tandem duplication mutant level, number, size, and interaction with NPM1 mutations in a large cohort of young adult patients 
62. Schnittger S, Bacher U, Kern W, et al., Prognostic impact of FLT3 ITD load in NPM1 mutated acute myeloid leukemia, Leukemia, 2011;25:1297-304

63. Ostronoff $F$, Othus $M$, Lazenby M, et al., Prognostic significance of NPM1 mutations in the absence of FLT3-internal tandem duplication in older patients with acute myeloid leukemia: SWOG and UK National Cancer Research Institute/Medical
Research Council report, J Clin Oncol, 2015:33:1157-64.

Research Council report, J Clin Oncol, 2015;33:1157-64.
64. Grimwade D, Freeman SD, Defining minimal residual disease in acute myeloid leukemia: which platforms are ready for "prime time"? , Blood, 2014;124:3345-55.

65. Kayser S, Walter RB, Stock W, et al., Minimal residual disease in acute myeloid leukemia-current status and future perspectives, Curr Hematol Malig Rep, 2015;10:132-44.

66. Ivey A, Hills RK, Simpson MA, et al., Assessment of Minimal Residual Disease in Standard-Risk AML, N Engl J Med, 2016;374:422-33.

67. Schiller J, Praulich I, Krings Rocha C, et al., Patient-specific analysis of FLT3 internal tandem duplications for the prognostication and monitoring of acute myeloid leukemia, Eur J Haematol, 2012;89:53-62.

68. Grunwald MR, Tseng LH, Lin MT, et al., Improved FLT3 internal tandem duplication PCR assay predicts outcome after allogeneic transplant for acute myeloid leukemia, Biol Blood Marrow Transplant, 2014,20:1989-95.

69. Lin MT, Tseng LH, Beierl K, et al., Tandem duplication PCR: an ultrasensitive assay for the detection of interna 2013;22:149-55.

70. Thol F, Kolking B, Damm F, et al., Next-generation sequencing for minimal residual disease monitoring in acute myeloid Chromosomes Cancer, 2012:51:689-95.

71. Dohner H, Weisdorf DJ, Bloomfield CD, Acute Myeloid Leukemia, Eng/J Med, 2015:373:1136-52.

72. Burnett AK, Russell NH, Hills RK, Higher daunorubicin exposure 2016;128:449-52.

73. Castaigne S, Pautas C, Terre C, et al., Effect of gemtuzumab zogamicin on survival of adult patients with de-novo acute myeloid leuka mia (ALFA 010 ). a randomised, open-label, phase 3 study, Lancet, 2012;379:1508-16.

74. Burnett AK, Megan $D$, Prentice $A G$, et al., A comparison of low trans retinoic acid for acute myeloid leukemila and high-risk intensive treatment, Cancer, 2007:109:1114-24.

75. Kantarijian HM, Thomas XG, Dmoszynska A, et al., Multicenter randomized, open-label, phase III trial of decitabine versus patient choice, with physician advice, of either supportive care or low-dose cytarabine for the treatment of older patients with newly diagnosed acute myeloid leukemia, I Clin Oncol, 2012;30:2670-7.

76. Dombret $\mathrm{H}$, Seymour JF, Butrym A, et al., International phase 3 study of azacitidine vs conventional care regimens in older patients with newly diagnosed AML with $>30 \%$ blasts, Blood 2015;126:291-9.

77. DeZern AE, Sung A, Kim S, et al., Role of allogeneic transplantation for FLT3/TDD acute myeloid leukemia: outcomes from 133 consecutive newly diagnosed patients from a single institution, Biol Blood Marrow Transplant, 2011:17:1404-9.

78. Brunet S, Labopin M, Esteve J, et al., Impact of FLT3 internal tandem duplication on the outcome of related and unrelated hematopoietic transplantation for adult acute myeloid leukemi in first remission: a retrospective analysis, $J$ Clin Oncol, in first remission

79. $\mathrm{Lin} \mathrm{PH}$, Lin CC, Yang HI, et al., Prognostic impact of allogeneic hematopoietic stem cell transplantation for acute myeloid leukemia patients with internal tandem duplication of FLT3, Leuk Res, 2013:37:287-92.

80. Ho AD, Schetelig J, Bochtler T, et al., Allogeneic stem cell transplantation improves survival in patients with acute myeloid leukemia characterized by a high allelic ratio of mutant FLT3-ITD, Biol Blood Marrow Transplant, 2016;22:462-9.

81. Kayser S, Benner A, Thiede C, et al., Pretransplant NPM1 MRD levels predict outcome after allogeneic hematopoietic stem cell transplantation in patients with acute myeloid leukemia, Blood Cancer 1 , 2016:6 6 e 449 .

82. Lancet JE, FLT3 inhibitors for acute myeloid leukemia, Clin Adv Hematol Oncol, 2015;13:573-5.

83. Kayser S, Levis MJ, FLT3 tyrosine kinase inhibitors in acute myeloid leukemia: clinical implications and limitations, Leuk Lymphoma, 2014;55:243-55.

84. Fischer T, Stone RM, Deangelo DJ, et al., Phase IIB trial of oral Midostaurin (PKC412), the FMS-like tyrosine kinase 3 receptor (FLT3) and multi-targeted kinase inhibitor, in patients with acute myeloid leukemia and high-risk myelodysplastic syndrome with either wild-type or mutated FLT3, I Clin Oncol, 2010;28:4339-45.

85. Wang ES, Yee K, Koh LP, et al., Phase 1 trial of linifanib (ABT-869)
(A) in patients with refractory or relapsed acute myeloid leukemia, in patients with refractory or relaps

86. Fiedler $W$, Mesters R, Tinnefeld $H$, et al., A phase 2 clinical study of SU5416 in patients with refractory acute myeloid leukemia Blood, 2003; 102:2763-7.

87. Giles $\mathrm{FJ}$, Stopeck AT, Silverman LR, et al., SU5416, a small molecule tyrosine kinase receptor inhibitor, has biologic activity in patients with refractory acute myeloid leukemia or myelodysplastic syndromes, Blood, 2003;102:795-801.

88. DeAngelo DJ, Stone RM, Heaney ML, et al., Phase 1 clinical results with tandutinib (MLN518), a novel FLT3 antagonist, in patients with acute myelogenous leukemia or high-risk myelodysplastic syndrome: safety, pharmacokinetics, and pharmacodynamics, Blood, 2006; 108:3674-81.

pharmacodynamics, Blood, 2006;108:3674-81.
89. Shiotsu Y, Kiyoi H, Ishikawa Y, et al., KW-2449, a nove multikinase inhibitor, suppresses the growth of leukemia cells with FLT3 mutations or T315I-mutated BCR/ABL translocation, Blood, 2009;114:1607-17.

. Smith BD, Levis M, Beran M, et al., Single-agent CEP-701, novel FLT3 inhibitor, shows biologic and clinical activity in patients with relapsed or refractory acute myeloid leukemia, Blood, 2004;103:3669-76.

91. Knapper S, Burnett AK, Littlewood T, et al., A phase 2 trial of the FLT3 inhibitor lestaurtinib (CEP701) as first-line treatment for older patients with acute myeloid leukemia not considered fit for intensive chemotherapy, Blood, 2006;108:3262-70.
Knapper S, Hills RK, Cavenagh JD, et al., A Randomised Knapper S, Hills RK, Cavenagh JD, et al., A Randomised
comparison of the sequential addition of the FLT3 inhibitor comparison of the sequential addition of the FLT3 Inhibitor
lestaurtinib (CEP701) to standard first line chemotherapy for FLT3-mutated acute myeloid leukemia: The UK experience. Presented at the 56th ASH Annual Meeting and Exposition December 6-9, 2014, San Francisco, CA, US. Abstract 3736.

93. Levis $\mathrm{M}$, Ravandi $\mathrm{F}$, Wang $\mathrm{ES}$, et al., Results from a rando
trial of salvage chemotherapy followed by lestaurtinib trial of salvage chemotherapy followed by lestaurtinib
for patients with FLT3 mutant AML in first relapse, Blood, 2011;117:3294-301.

94. Sato T, Yang X, Knapper S, et al., FLT3 ligand impedes the efficacy of FLT3 inhibitors in vitro and in vivo, Blood 2011;117:3286-93

95. Knapper S, Russell N, Gilkes A, et al., A randomised assessment of adding the kinase inhibitor lestaurtinib to 1 st-line chemotherapy for FLT3-mutated AML, Blood, 2016: doi: https:// doi.org/10.1182/blood-2016-07-730648.

6. Shah NP, Talpaz M, Deininger MW, et al., Ponatinib in patients with refractory acute myeloid leukaemia: findings from a phas 1 study, Br J Haematol, 2013;162:548-52.

97. FDA, FDA Drug Safety Communication: FDA requires multiple new safety measures for leukemia drug Iclusig; company expected to resume marketing. Available at: www.fda.gov/
Drugs/DrugSafety/ucm379554.htm (accessed 1 March 2016). 98. Hochhaus A, Cortes JE, Kim D-W, et al., Efficacy and safety of ponatinib in CP-CML patients by number of prior tyrosine of ponatinib in CP-CML patients by number of prior tyrosine
kinase inhibitors: 4 -year follow-up of the phase 2 PACE trial. Presented at the 57th ASH Annual Meeting and Exposition, December 5-8, 2015, Orlando, FL, Abstract 4025.

99. Cortes JE, Kim DW, Pinilla-lbarz J, et al., A phase 2 trial of ponatinib in Philadelphia chromosome-positive leukemias, N Eng/ J Med, 2013;369:1783-96.

100. NCT02829840, Dose-Escalation Study of Ponatinib, a FLT3 Inhibitor, With and Without Combination of 5-Azacytidine, in Available at: https://clinicaltrials.gov/ct2/show/NCT02829840 Available at: https://clinic
(accessed 22 May 2017).

101. Fiedler W, Kayser S, Kebenko M, et al., A phase I/II study of sunitinib and intensive chemotherapy in patients over 60 years of age with acute myeloid leukaemia and activating FLT3

102. Metzelder SK, Schroeder T, Finck A, et al., High activity of sorafen ib inchia synergizes with allo-immune effects
responses, Leukemia, 2012;26:2353-9.

103. Borthakur G, Kantarjian H, Ravandi F, et al., Phase I study of sorafenib in patients with refractory or relapsed acute of sorafenib in patients with refractory or
leukemias, Haematologica, 2011;96:62-8.

104. Röllig C, Serve H, Huttmann A, et al., Addition of sorafenib versus placebo to standard therapy in patients aged 60 years or younger with newly diagnosed acute myeloid leukaemia (SORAML): a multicentre, phase 2, randomised controlled trial, Lancet Oncol, 2015;16:1691-9.

105. Ravandi F, Cortes JE, Jones D, et al., Phase I/II study of combination therapy with sorafenib, idarubicin, and cytarabine in younger patients with acute myeloid leukemia, I Clin Oncol, 2010;28:1856-62.

106. Serve H, Krug U, Wagner R, et al., Sorafenib in combination with intensive chemotherapy in elderly patients with acute myeloid leukemia: results from a randomized, placebo-controlled trial, J Clin Oncol, 2013;31:3110-8.

107. Uy GL, Mandrekar SJ, Laumann K, et al., A phase 2 study incorporating sorafenib into the chemotherapy for older adults Blood Advances, 2017;1:331-40.

108. Ravandi F, Alattar ML, Grunwald MR, et al., Phase 2 study of azacytidine plus sorafenib in patients with acute myeloid leukemia and FLT-3 internal tandem duplication mutation, Blood, 2013;121:4655-62.

109. Stone R, Madrekar SJ, Sanford BL, et al,. Midostaurin plus chemotherapy in FLT3-mutated AML CALGB 10603 (Alliance), chemotherapy in FLT3-mutated
submitted for publication, 2017 .

110. Weisberg E, Boulton C, Kelly LM, et al., Inhibition of mutant FLT3 receptors in leukemia cells by the small molecule tyrosine FLT3 receptors in leukemia cells by the small molect
kinase inhibitor PKC412, Cancer Cell, 2002;1:433-43.

111. Stone RM, Fischer T, Paquette R, et al., Phase IB study of the FLT3 kinase inhibitor midostaurin with chemotherapy in younger newly diagnosed adult patients with acute myeloid Teukemia, Leukemia, 2012;26:2061-8.

Mandrekar S, Sanford BL, et al., The multi-kinase inhibitor midostaurin prolongs survival compared with placebo in combination with daunorubicin/cytarabine induction, high-dose cytarabine consolidation, and as maintenance therapy in newly
diagnosed acute myeloid leukemia patients age 18-60 with FLT3 mutations: an international prospective randomized placebocontrolled double-blind trial (CALGB 10603/RATIFY [Alliance]). Presented at the American Society of Hematology 57 th A
Meeting; Orlando, Florida, December 6, 2015; abstract 6.

113. Novartis, Novartis receives FDA approval for Rydapt in newly diagnosed FLT3-mutated acute myeloid leukemia (AML) and three types of systemic mastocytosis (SM). Available at: fda-approval-rydaptr-newly-diagnosed-fit3-mutated-acute (accessed 22 May 2017).

14. Schlenk R, Döhner K, Salih H, et al., Midostaurin in combination with intensive induction and as single agent maintenance therapy after consolidation therapy with allogeneic hematopoietic stem cell transplantation or high-dose

115. Cooper BW, Kindwall-Keller TL, Craig MD, et al., A phase I study of midostaurin and azacitidine in relapsed and elderly AML patients, Clin Lymphoma Myeloma Leuk, 2015;15:428-32 e2. 6. Strati P, Kantarjian $\mathrm{H}$, Ravandi F, et al., Phase I/II trial of the combination of midostaurin (PKC412) and 5-azacytidine for
patients with acute myeloid leukemia and myelodysplastic patients with acute myeloid leukemia and

117. Fathi A, Levis M, FLT3 inhibitors: a story of the old and the new, Curr Opin Hematol, 2011;18:71-6.

118. Cortes JE, Kantarjian H, Foran JM, et al., Phase I study of quizartinib administered daily to patients with relapsed or refractory acute myeloid leukemia irrespective of FMS-like
tyrosine kinase 3-internal tandem duplication status, I Clin tyrosine kinase 3-intern

119. Levis MJ, Perl AE, Dombret H, et al, Final results of a phase 2 open-label, monotherapy efficacy and safety study of quizartinib (AC220) in patients with FLT3-ITD positive or negative relapsed/refractory acute myeloid leukemia after transplantation, Blood, 2012;120;673.

120. Schiller GJ, Tallman MS, Goldberg SL, et al., Final results of a randomized phase 2 study showing the clinical beneft of quizartinib (AC220) in patients with FLT3-ITD positive
relapsed or refractory acute myeloid leukemia, I Clin Oncol relapsed or refractory acute

121. Erba HP, Levi MJ, Sekeres MA, et al., Phase 3 (P3) study of quizartinib or placebo with induction and consolidation chemotherapy and as maintenance in patients with newly QUANTUM-First study, J Clin Oncol, 2016;34:suppl; abstr QUANTUM

122. Randhawa JK, Kantarjian HM, Borthakur G, et al., Results of a phase II study of crenolanib in relapsed/refractory acute myeloid leukemia patients (pts) with activating FLT3 mutations,

23. Collins R, Kantarjian HM, Levis MJ, et al., Clinical activity of crenolanib in patients with D835 mutant FLT3-positive
relapsed/refractory acute myeloid leukemia (AML), I Clin Oncol, 2014:32:(15 suppl): 7027 .

124. Perl AE, Altman JK, Cortes JE, et al. , Final results of the Chrysalis trial: a first-in-human phase 1/2 dose-Escalation with relapsed/refractory acute myeloid leukemia, Blood, 2016:128:abstr 1069.

125. Perl AE, Cortes JE, Strickland SA, et al., A phase 3, open-label, randomized study of the FLT3 inhibitor gilteritinib versus salvage chemotherapy in adults with first relapse or primary refractory FLT3 mutation-positive acute myeloid leukemia, I Clin Oncol, 2016:34:suppl; abstr TPS7072.

126. Man CH, Fung TK, Ho C, et al., Sorafenib treatment of FLT3$\operatorname{ITD}(+)$ acute myeloid leukemia: favorable initial outcome and mechanisms of subsequent nonresponsiveness associated with the emergence of a D835 mutation, Blood, 5133-43.

127. Yang $X$, Sexauer $A$, Levis $M$, Bone marrow stroma-mediated resistance to FLT3 inhibitors in FLT3-ITD AML is mediated by persistent activation of extracellular regulated kinase, $\mathrm{Br} J$ Haematol, 2014;164:61-72.

128. Parmar A, Marz S, Rushton S, et al., Stromal niche cells protect early leukemic FLT3-ITD+ progenitor cells against first-generation FLT3 tyrosine kinase inhibitors, Cancer Res, 2011;71:4696-706.

129. Breitenbuecher F, Markova B, Kasper S, et al., A novel molecular mechanism of primary resistance to FLT3-kinase inhibitors in AML, Blood 2009:113:4063-73.

130. NCT00819546, RAD001 in Combination With PKC412 in Patients With Relapsed, Refractory or Poor Prognosis AML or MDS. Availablet at: https://clinicaltrials.gov/show/NCT00819546?link_ type=CLINTRIALGOV\&access_num=NCT00819546 (accessed 1 March 2016).

131. Lam SS, Ho ES, He BL, et al., Homoharringtonine (omacetaxine mepesuccinate) as an adjunct for FLT3-ITD acute myeloid memia, Sci Trans/ Med, 2016;8:359ra129.

132. Weisberg E, Liu Q, Nelson E, et al., Using combination therapy to override stromal-mediated chemoresistance in mutant FLT3positive AML: synergism between FLT3 inhibitors, dasatinib/ multi-targeted inhibitors and JAK inhibitors, Leukemia, 2012;26:2233-44.

133. Zhou J, Bi C, Janakakumara JV, et al., Enhanced activation of STAT pathways and overexpression of survivin confer
resistance to FLT3 inhibitors and could be therapeutic targets in AML, Blood, 2009:113:4052-62.

134. Wander SA, Hennessy BT, Slingerland JM, Next-generation mTOR inhibitors in clinical oncology: how pathway complexity

135. Green AS, Maciel IT, Hospital MA, et al., Pim kinases modulate resistance to FLT3 tyrosine kinase inhibitors in FLT3-ITD acute myeloid leukemia, Sci Adv, 2015;1:e1500221.

136. Novotny-Diermayr V, Hart S, Goh KC, et al., The oral HDAC inhibitor pracinostat (SB939) is efficacious and synergistic with the JAK2 inhibitor pacritinib (SB15

137. Knapper S, Grech A, Cahalin P, et al, An evaluation of tyrosine kinase inhibitor pacritinib in patients with relapsed FLT3mutated acute myeloid leaukaemia (the UK NRCI AML17 study). Congress, June 9-12, 2016, Copenhagen, Denmark. Abstra P184. 